N94- 31102

\title{
Convection and Electrodynamic Signatures in the Vicinity of a Sun-aligned Arc: Results from the Polar Acceleration Regions and Convection Study (Polar ARCS)
}

\author{
L. A. Weiss, ${ }^{1}$ E. J. Weber, ${ }^{2}$ P. H. Reiff, ${ }^{1}$ J. R. Sharber, ${ }^{3}$ J. D. Winningham, ${ }^{3}$ \\ F. Primdahl, ${ }^{4}$ I. S. Mikkelsen, ${ }^{5}$ C. Seifring, ${ }^{6}$ and E. M. Wescott ${ }^{7}$
}

\begin{abstract}
An experimental campaign designed to study high-latitude auroral arcs was conducted in Sondre Stromfjord, Greenland, on February 26, 1987. The Polar Acceleration Regions and Convection Study (Polar ARCS) consisted of a coordinated set of ground-based, airborne, and sounding rocket measurements of a weak, sun-aligned arc system within the duskside polar cap. A rocket-borne barium release experiment, two DMSP satellite overflights, all-sky photography, and incoherent scatter radar measurements provided information on the large-scale plasma convection over the polar cap region while a second rocket instrumented with a DC magnetometer, Langmuir and electric field probes, and an electron spectrometer provided measurements of small-scale electrodynamics. The large-scale data indicate that small, sun-aligned precipitation events formed within a region of antisunward convection between the duskside auroral oval and a large sun-aligned arc further poleward. This convection signature, used to assess the relationship of the sun-aligned arc to the large-scale magnetospheric configuration, is found to be consistent with either a model in which the arc formed on open field lines on the dusk side of a bifurcated polar cap or on closed field lines threading an expanded low-latitude boundary layer, but not a model in which the polar cap arc field lines map to an expanded plasma sheet. The antisunward convection signature may also be explained by a model in which the polar cap arc formed on long field lines recently reconnected through a highly skewed plasma sheet. The small-scale measurements indicate the rocket passed through three narrow $(\leq 20 \mathrm{~km})$ regions of low-energy $(\leq 100 \mathrm{eV}$ ) electron precipitation in which the electric and magnetic field perturbations were well correlated. These precipitation events are shown to be associated with regions of downward Poynting flux and small-scale upward and downward field-aligned currents of $1-2 \mu \mathrm{A} / \mathrm{m}^{2}$. The paired field-aligned currents are associated with velocity shears (higher and lower speed streams) embedded in the region of antisunward flow.
\end{abstract}

\section{INTRODUCTION}

The "polar cap boundary," the boundary between the bright, approximately circular, oval of auroral emission and the darker, interior polar region, has been variously defined on the basis of -magnetospheric topology (the mapping of an assumed open/closed field line boundary) [Birn et al., 1991; Elphinstone et al., 1991], the locus of the electric field (convection) reversal [Heelis et al., 1980; Torbert et al., 1981], and the poleward extent of plasma sheet particle

\footnotetext{
${ }^{1}$ Department of Space Physics and Astronomy, Rice University, Houston, TX

${ }^{2}$ Phillips Laboratory, Hanscom AFB, Bedford, MA

${ }^{3}$ Southwest Research Institute, San Antonio, TX

${ }^{4}$ Danish Space Research Institute, Lyngby, Denmark

5 Danish Meteorological Institute, Copenliagen, Denmark

${ }^{6}$ Naval Research Laboratory, Washington, DC

${ }^{7}$ Geophysical Institute, University of Alaska, Fairbanks, AK
}

Auroral Plasma Dynamico

Geophysical Monograph 80

Copyright 1993 by the American Geophysical Union. precipitation [Winningham and Heikkila, 1974; Meng, 1981; Makita et al., 1988; Rich et al., 1990]. Although these boundaries may be located near one another, they often do not coincide and become especially difficult to interpret during times of northward Interplanetary Magnetic Field (IMF $B_{z}>0$ ) when sun-aligned arcs, additional field-aligned current systems, and highly structured electric fields can extend over the entire high-latitude region [Burke et al., 1979, 1982; Iijima et al., 1984; Hardy, 1984; Zanetti et al., 1990].

Polar cap aurorae are observed in the polar cap during quiet magnetospheric times when the auroral oval is least active, (i.e., when the IMF $B_{z}$ component is northward), and are predominantly aligned along the earth-sun line [e.g., Lassen and Danielsen, 1978; 1989]. A common type of polar cap aurora is created by precipitating electrons with average energies between 50 and $300 \mathrm{eV}$, resulting in weak (usually subvisual) multiple, F-layer arcs [Weber and Buchau, 1981; Hardy, 1984]. A less common type of polar cap aurora is one which stretches across the entire polar cap from noon to midnight, forming what appears from high altitude spacecraft as a 'theta' aurora [Frank et al., 1986; Niclsen et al., 1990]. Bright sun-aligned arcs are also often observed at the poleward 
boundary of a region of soft electron precipitation extending poleward from one or both edges of the auroral oval, resulting in a ' $D$ ' or 'teardrop' shaped polar cap, respectively [Murphree and Cogger, 1981; Elphinstone et al., 1990; Hones et al., 1989]. Recent attempts at mapping the open/closed field line boundary to the ionosphere as a function of IMF have had moderate success in reproducing the observed changes in polar cap shapes [Birn et al., 1991; Elphinstone et al., 1991; Toffoletto and Hill, 1990; 1992].

Like arcs in the auroral oval, polar cap aurorae are believed to be the optical signature of upward field-aligned currents where $\nabla \cdot \Sigma E<0$ [Reiff et al., 1978; Lyons, 1980; Burke et al., 1982; Chiu and Gorney, 1983; Chiu, 1989; Valladares and Carlson, 1991]. On the dayside, the electrons carrying the majority of this upward current have either been interpreted as precipitating on closed field lines threading the LLBL [Lassen and Danielsen, 1989; Lundin et al., 1990] or on open field lines threading the plasma mantle [Newell et al., 1991]. At other local times, it has been suggested that weak, polar cap arcs result from the precipitation of accelerated polar rain electrons on open field lines [Hardy et al., 1982; Burke et al., 1982; Gussenhoven and Mullen, 1989], or from plasma sheet or low latitude boundary layer electrons on closed field lines [Meng, 1981; Murphree et al., 1982; Lundin and Evans, 1985; Lundin et al., 1990].

The Polar Acceleration Regions and Convection Study (Polar ARCS) was designed to provide the simultaneous convection and electrodynamic information needed to investigate the magnetospheric topology and generation mechanisms of high-latitude polar cap arcs. This paper summarizes the primary measurements and results of this study, which can be divided into two categories: large-scale phenomena, which lead to the examination of different models of polar cap morphology; and smaller-scale phenomena, which allow the investigation of the electrodynamic structure of the arcs. More detailed descriptions of the instruments, measurements, and results of Polar ARCS can be found in Weiss [1991].

\section{EXPERIMENT DESCRIPTION}

Polar ARCS consisted of a coordinated set of ground-based, airborne, and in situ measurements of high-latitude sun-aligned arcs over Sondrestrom, Greenland, on February 26, 1987. Three charges of barium were injected into the F-region ionosphere immediately prior to the launch of a Black Brant IX instrumented with a DC magnetometer, Langmuir and electric field probes, and an electron spectrometer. Simultaneous electron density and line-of-sight velocity measurements were made by the Sondrestrom Incoherent Scatter Radar, and all-sky images of auroral activity were recorded using the All-Sky Imaging Photometer (ASIP) aboard the Airborne Ionospheric Observatory (AIO).

Figure 1 (a) summarizes, in geographical coordinates, the relative orientations of a large, sun-aligned arc observed by the ASIP, the ground trajectories of two DMSP satellite passes occurring within 30 minutes of launch, and the position of the auroral oval (as inferred from the DMSP electron measurements and ground-based all-sky images from Dye 2). The fields-ofview of the ASIP and the radar are denoted by the circular and semi-circular regions, respectively. The rocket's ground trajectory is shown as a straight line stretching from Sondrestrom to the northeast, and the three ionized barium tracks (resulting from rocket-borne releases just prior to launch of the instrumented rocket) are shown as irregular lines at the end of the rocket trajectory. The sun-aligned arc is oriented along a line $50^{\circ}$ west of north, between the magnetic meridian (39 ${ }^{\circ}$ west of north) and the sun-aligned direction $\left(-60^{\circ}\right.$ west of north).

The $6300 \AA$ ASIP images indicated the presence of diffuse, sun-aligned precipitation throughout the region over Sondrestrom between the sun-aligned arc and the auroral oval. The dawn - dusk F6 number flux spectrograms [Weiss, 1991] show a clearly defined region of enhanced electron and ion precipitation over the middle of the polar cap, indicative of the presence of a transpolar (theta) aurora [Frank et al., 1986] at the time of the pass; the theta aurora would appear just off the scale of Figure 1 (a), to the upper right. The theta aurora, auroral oval, and sun-aligned arc are -shown in MLT/IL coordinates in Figure 1 (b).

The instrumented rocket was launched at 2349:10 UT $(-22$ MLT) to the northeast, reaching an apogee of $380 \mathrm{~km}$ and covering a ground range of $166 \mathrm{~km}$. Shortly after launch, the nosecone portion of the rocket separated from the main payload in order to provide a magnetically clean environment for the DC science magnetometer aboard this separated section. Data were obtained from both payloads for nearly 600 seconds after launch. Electron precipitation measurements indicate that the rocket passed through three narrow $(\leq 20 \mathrm{~km})$ regions of low-energy $(\leq 100 \mathrm{eV}$ ) electron precipitation. These events are interpreted as small-scale structures that lie within the region of weak, sun-aligned precipitation in the region between the auroral oval and the large sun-aligned arc in the all-sky images. Shortly after the decision to launch was made, the large arc began to fade from a pre-launch brightness of about $300 \mathrm{R}$ (subvisual) to less than $100 \mathrm{R}$ by $2358 \mathrm{UT}$. This type of weak, F-region sun-aligned arc is typical of those identified by Weber and Buchau [1981] as resulting from the structured precipitation of electrons with average energies of only a few hundred $\mathrm{eV}$.

Although IMP-8 was in the magnetosheath at the time of the experiment (and thus no IMF measurements are available), the presence of sun-aligned arcs, the precipitation over the center of the polar cap, and the contracted state of the auroral oval (Figure 1 (b)) argue that the IMF $\mathrm{B}_{\mathrm{z}}$ component was northward during this period. Moreover, the geomagnetic three-hourly average $K_{p}$ index was 1 for the six hours prior to and three hours after the flight, confirming that the magnetosphere was in a very quiet state.

\section{ObSERVATIONS}

\subsection{Large-scale measurements}

The large-scale Polar ARCS measurements consist of the allsky images, incoherent scatter radar measurements, DMSP 


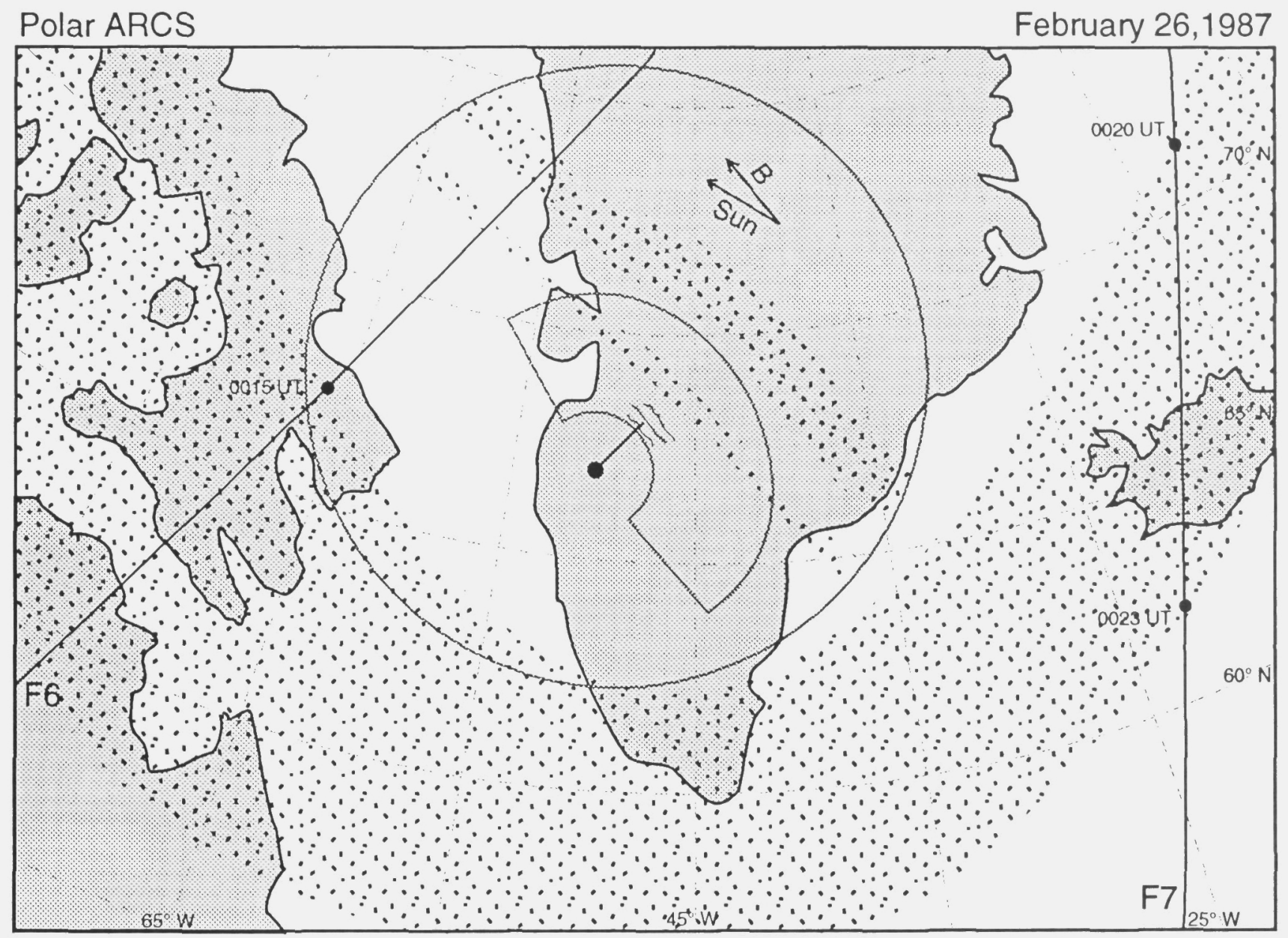

Fig. 1(a). A geographic diagram showing the location and orientation of the sun-aligned arc and auroral oval, and the spatial relationship between the different measurement regions. The large circle represents the ASIP field-of-view and the smaller partial circle is the radar field-of-view. The instrumented rocket track is denoted by the line stretching from Sondrestrom to the northeast. The motion of the three barium tracks are shown as irregular lines at the end of the rocket trajectory.

particle measurements, barium convection data, and DC convection electric field measurements. The all-sky images and DMSP overflight data are used to establish the scale and relative orientation of the sun-aligned arc and auroral oval, as shown in Figures 1 (a) and (b). The ionospheric convection signature in the region between the sun-aligned arc and the dusk-side auroral oval is inferred from the remaining independent measurements: the motion of the three barium jets, the radar 1.o.s. velocities, and the rocket electric field data.

A detailed description of the barium release experiment is given by Mikkelsen [1987]. The horizontal motion of the three barium jets (projected along the field line to $100 \mathrm{~km}$ altitude) is shown in geographic coordinates in Figure 2. The rocket's ground trajectory, the three observation sites, and the rocket range east of the radar have also been noted. The horizontal drift speed and direction was determined by plotting the position of the three ionized jets (labeled with time markers in minutes after $2300 \mathrm{UT}$ ) in planes perpendicular and parallel to the local magnetic meridian plane; the result was found to be an average plasma drift speed of $440 \mathrm{~m} / \mathrm{s}$ in a direction $50^{\circ}$ east of south (i.e., the antisunward direction).

The plasma convection between the precipitation events and the large sun-aligned are is corroborated by the radar l.o.s. velocity measurements. Prior to and during the instrumented rocket flight, the Sondrestrom radar operated in a mode combining both azimuth and elevation scans, directly measuring the electron number density, line-of-sight (l.o.s.) plasma velocity, and ion and electron temperatures in the region northwest of the rocket trajectory (see Figure 1(a)). Figure 3 shows l.o.s. velocity measurements for two combined azimuth scans from 2333:07 - 2340:45 UT. The 1.o.s, vectors indicate antisunward flow at approximately $500 \mathrm{~m} / \mathrm{s}$ in a direction slightly east of the magnetic meridian, or about $50^{\circ}$ east of south. Figures 4 (a) and (b) show electron number densities and l.o.s. velocities from an elevation scan from 2346:17 




Fig. 1(b). The location of the sun-aligned arc (dark gray bar) and the tracks of the Sondrestrom ground station (from 2300 - 0030 UT) and DMSP F-6 and F-7 satellites in Magnetic Local Time / Invariant Latitude (MLT / IL) format. The observed portion of the transpolar arc and the auroral oval (as inferred from the DMSP spectrograms) are shown in light gray.

2349:11 UT in a plane perpendicular to the magnetic meridian. The region of enhanced density at a range of $600 \mathrm{~km}$ is associated with the large, sun-aligned arc seen in the ASIP images. Negligible 1.o.s. velocity measurements indicate that the convection is either negligible or is nearly perpendicular to this plane, i.e. along the magnetic meridian. If the latter interpretation is true, the measurements agree with and extend the region of anti-sunward convection determined by the motion of the barium jets.

Finally, the rocket-borne electric field measurements indicate that the large-scale (convection) electric field in the region traversed by the rocket had an average westward component of $10 \mathrm{mV} / \mathrm{m}$ and average southward component of $12 \mathrm{mV} / \mathrm{m}$, corresponding to plasma convection in a direction $-50^{\circ}$ east of south at an average velocity of $300 \mathrm{~m} / \mathrm{s}$. Superposed on these large-scale components (not shown) are deviations occurring on time scales of $40-60$ seconds associated with the precipitation events and small scale current structures traversed by the rocket (see Figures 5 and 6 ).

\subsection{Smaller-scale measurements}

The smaller scale data consist of measurements made by the electron spectrometer, electric field detector, magnetometer, and Langmuir probe during the instrumented rocket flight. Three electron precipitation events were detected during the flight by a tophat electrostatic analyzer [Sharber et al., 1988]. The events have the appearance of high latitude arcs but are very narrow in extent, the widest being about $20 \mathrm{~km}$. The precipitating energy flux profiles in the energy range $1.0 \mathrm{eV}$ $1.0 \mathrm{keV}$ integrated over the downcoming hemisphere for the first two precipitation events are shown in the top panel of Figures 5 and 6 . The events are very weak, with an average electron energy $\leq 100 \mathrm{eV}$ and a maximum energy flux of 0.12 $\mathrm{erg} / \mathrm{cm}^{2} \mathrm{~s}$. Since the third precipitation event was weaker yet, the electrodynamics study will be restricted to the first two events. The horizontal scale of Figures 5 and 6 corresponds to $22 \mathrm{~km}$ and $27 \mathrm{~km}$, respectively.

During the course of the flight, measurements of the ambient electric and magnetic fields were made by a double-probe electric field detector and a three-axis fluxgate magnetometer



Fig. 2. The horizontal motion of the three barium jets plotted in geographic coordinates at a reference altitude of $100 \mathrm{~km}$. Time markers along each trajectory are in minutes after 2300 UT. The tracks of the neutral barium / strontium clouds are indicated by squares and the firing directions of the three shaped charges are indicated by arrows. Note that the direction of magnetic north (azimuth of the line perpendicular to invariant latitude, $-27^{\circ}$ ) differs from that of the magnetic meridian plane (azimuth of the plane passing through the local magnetic field line and local zenith, $-39^{\circ}$ ) 


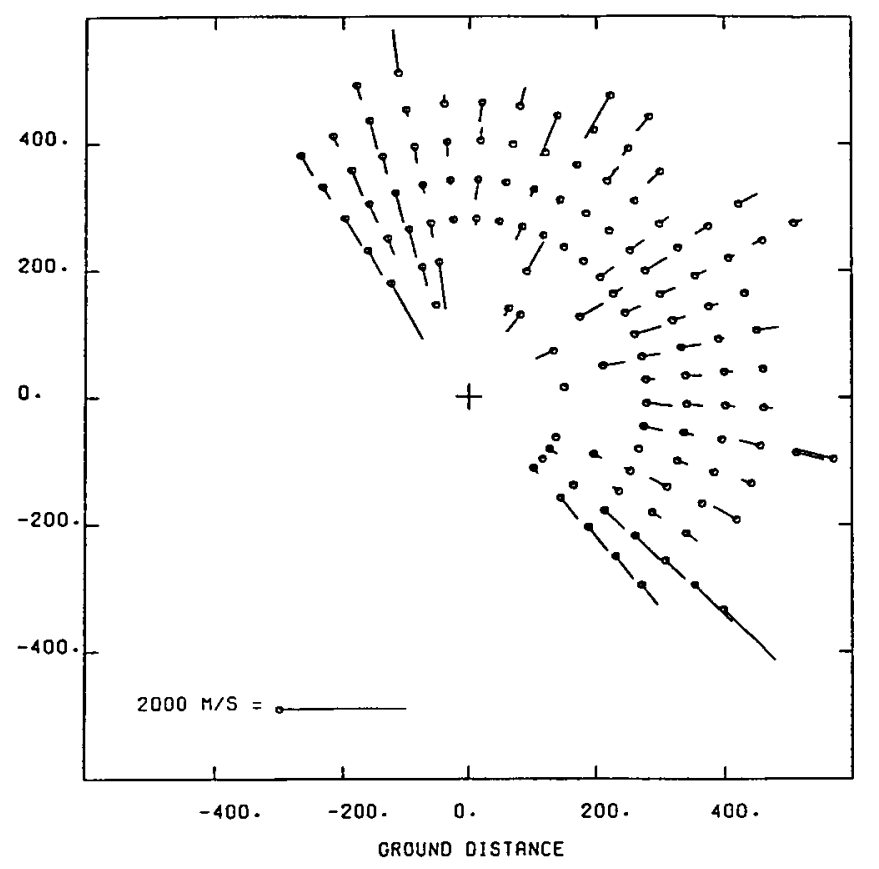

Fig. 3. Line-of-sight velocity measurements from two combined azimuth scans (at $35^{\circ}$ elevation angle) from 2333:07 - 2340:45 UT. The sunward direction is $-60^{\circ}$ west of north, which is at the top of the figure. Ground distances are in $\mathbf{k m}$.

[Primdahl, 1979]. After the appropriate data reduction, the perturbation electric and magnetic field components were rotated into a coordinate system in which $x$ is perpendicular to the arc (positive eastwards), $y$ is parallel to the arc (positive northward), and $z$ is directed upward antiparallel to the magnetic field. The cross-arc electric field perturbation $\left(\delta \mathrm{E}_{\mathrm{x}}\right)$ and arc-aligned magnetic field perturbation $\left(\delta \mathrm{B}_{\mathrm{y}}\right)$ are shown in the second panel of Figures 5 and 6 . Both sets of data have been smoothed to remove the spin period oscillation, and the average convection electric field $(-15 \mathrm{mV} / \mathrm{m})$ was subtracted from $E_{x}$ for the purpose of highlighting the anticorrelation between $E_{x}$ and $\delta B_{y}$ (discussed in Section 4.2). The electric field data are consistent with arc-aligned ionospheric shear flows embedded in a region of anti-sunward convection. No significant cross-arc component of the flow (i.e., arc-aligned electric field) remained after the rotation.

The Langmuir probe measured the thermal electron density and temperature throughout the flight. No significant enhancement in electron density was detected in association with the precipitation events, a result consistent with the softness of the precipitation [e.g., Roble and Rees, 1977]. In contrast, significant increases in the electron temperature were observed in the precipitation regions due to the short time constant for heating the electron gas at F-layer altitudes. The average background Pedersen conductivity in the region traversed by the rocket was found to be 0.6 mho using the measured electron number density profile.

\section{DisCusSION}

\subsection{Morphology of the Polar Cap}

The large-scale measurements presented in Section 3.1 are used in this section to explore the feasibility of four different models of polar cap morphology that have been used to explain the presence of weak sun-aligned arcs. These models are here called the 'open' [Hardy et al., 1982; Burke et al., 1982; Chiu, 1989; Gussenhoven and Mullen, 1989], 'bifurcated tail' [Frank et al., 1982; Kan and Burke, 1985; Frank and Craven, 1988; Toffoletto and Hill, 1990], 'expanded plasma sheet' [Meng, 1981; 1988; Murphree et al., 1982; Makita et al., 1991], and 'expanded low-latitude boundary layer (LLBL)' [Lundin and Evans, 1985; Lundin et al., 1990] models. A fifth model, which relies on the rotation of the tail $x$-line, is also introduced and discussed briefly [Reiff et al. 1992].

Figure 7 schematically summarizes these five different models. The left side of the figure shows distant $\left(x \geq 10 \mathrm{R}_{\mathrm{E}}\right)$ cross-sections of the northern magnetotail lobe $(y-z$ plane, looking from the distant tail sunward), while the right-hand column displays the corresponding topology of the highlatitude ionosphere, including the predicted ionospheric plasma flow (dotted lines). Regions of antisunward plasma
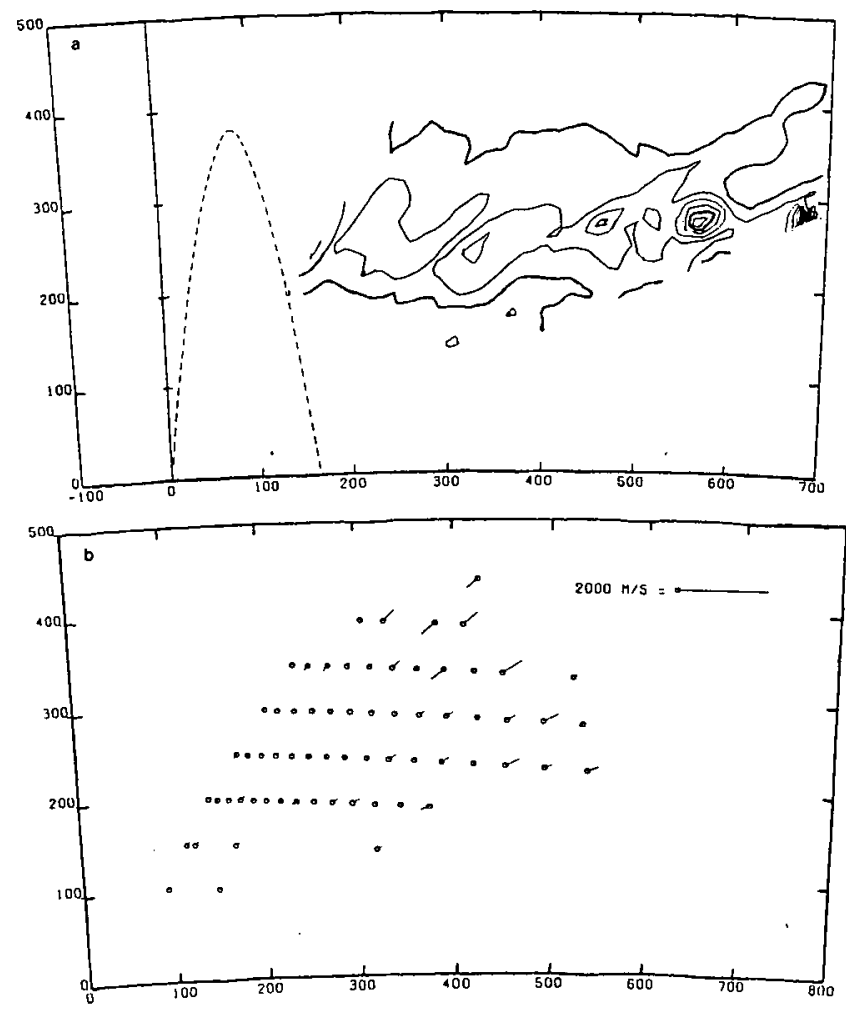

Fig. 4. (a) Electron number density and (b) line-of-sight velocity measurements from an elevation scan from 2346:17 - 2349:11 UT in a plane perpendicular to the magnetic meridian. The rocket's trajectory is shown in the top panel. The density contours are plotted in increments of $0.5 \times 10^{5}$, reaching a peak density of $3.0 \times 10^{5} \mathrm{~cm}^{-3}$. 




Fig. 5. Relationship between (a) particle precipitation, $(b)$ cross-arc and parallel electric and magnetic field perturbations, $\delta \mathrm{E}_{\mathrm{x}}$ and $\delta \mathrm{B}_{\mathrm{y}},(c)$ field-aligned current density, and (d) Poynting flux for the first precipitation event.

convection in the tail (LLBL and lobe) are labeled with circled dots, while regions of sunward convection (PSBL and plasma sheet) are denoted by circled crosses. In both the magnetotail and ionosphere, closed field line regions are shown in light gray (LLBL), medium gray (plasma sheet), or dark gray (PSBL), while open field line regions are shown in white. We have denoted the ionospheric projection of the PSBL as the boundary region separating open and closed field lines. Counter-streaming particle distributions and velocity dispersed ions, on the other hand, would only be observed in that portion of the PSBL in which there is a merging outflow. The (observed) sun-aligned arc is designated by the short solid line at -22 MLT and the (inferred) theta aurora is shown as a solid line extending from noon to midnight across the polar cap.

Polar cap arcs have been argued to occur on open field lines on the basis of two types of observations: the measurement of electron spectra within polar cap arcs with the appearance of an accelerated polar rain (magnetosheath) distribution [Hardy et al., 1982; Burke et al., 1982] and, secondly, observations of sun-aligned arcs imbedded in regions containing simultaneous solar flare (> $100 \mathrm{keV}$ ) and polar rain electron precipi- tation [Gussenhoven and Mullen, 1989]. If the Polar ARCS data are interpreted in terms of an open model, shown in Figure 7 (a), the weak, sun-aligned arc would map along open field lines to a position in the tail lobe denoted by the black dot. Antisunward convection of plasma along these open field lines maps directly to the polar ionosphere, where the arc is shown imbedded in a region of antisunward convection. Although the ionospheric convection in Figure 7 (a) has been depicted as a four-cell pattern with an extended region of sunward flow over the center of the polar cap (i.e., $B_{y} \approx 0$ ), alternate versions of the open model for northward IMF with a strong $B_{y}$ component consist of three-cell convection patterns [Reiff and Burch, 1985; Chiu, 1985]. The (inferred) theta aurora is depicted at the central convection reversal of the dawn NBZ Birkeland current region [Reiff and Burch, 1985; Lyons, 1985; Zanetti et al., 1990].

In a bifurcated tail interpretation, Figure 7 (b), the sunaligned arc also maps to the open tail lobe, but the transpolar aurora instead maps to a region of closed field lines extending upward from the central plasma sheet. The bifurcated tail model was originally developed to explain observations of

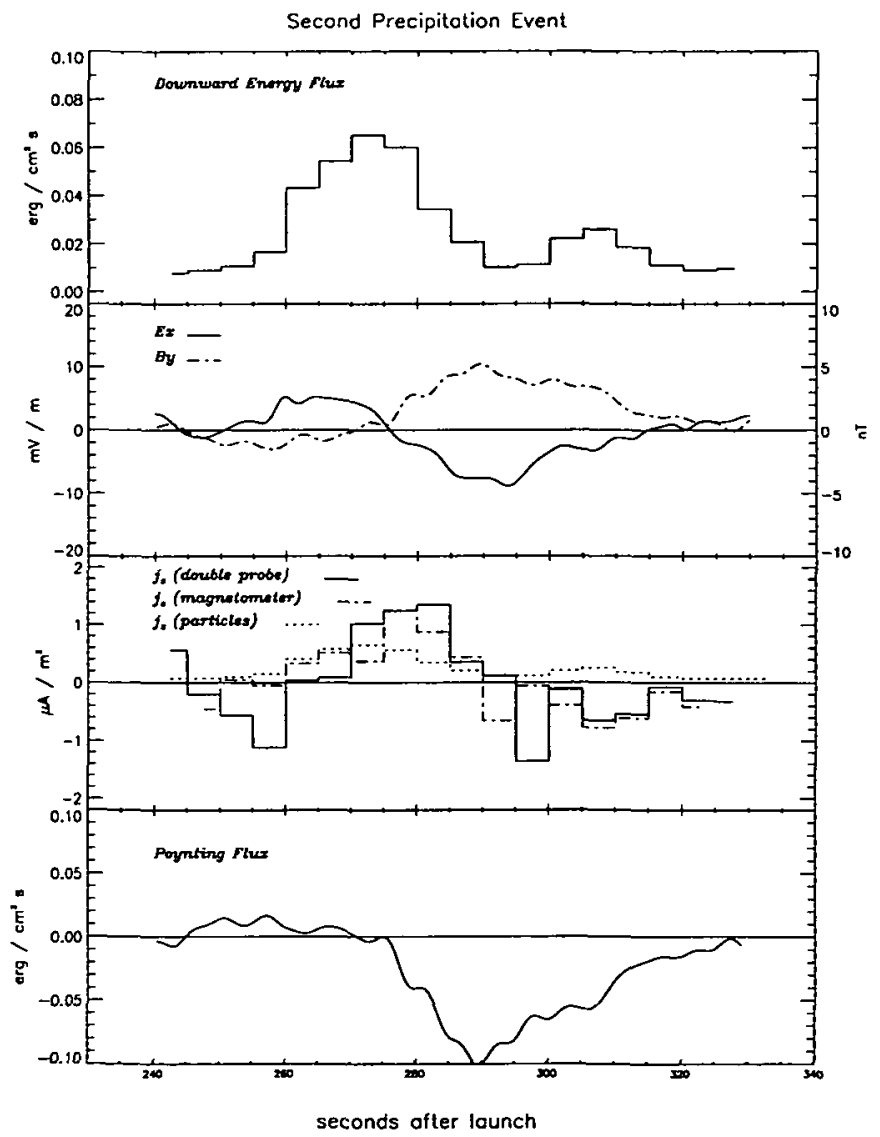

Fig. 6. Relationship between (a) particle precipitation, $(b)$ cross-arc and parallel electric and magnetic field perturbations, $\delta \mathrm{E}_{\mathrm{x}}$ and $\delta \mathrm{B}_{\mathrm{y}},(c)$ field-aligned current density, and (d) Poynting flux for the second precipitation event. 



$\angle$ plasma sheet

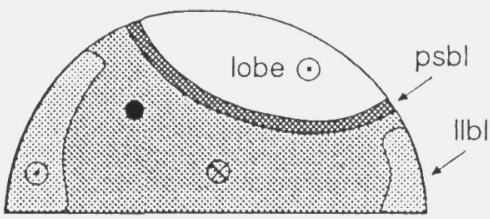

$£$ plasma sheet

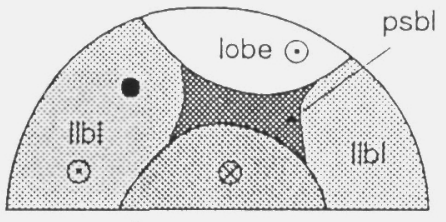

$\angle$ plasma sheet

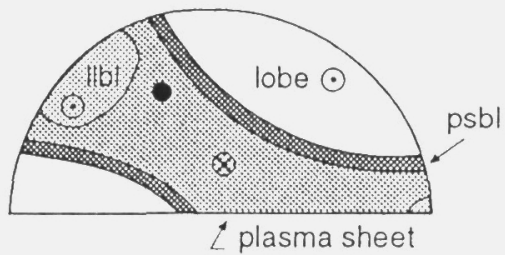

(a)

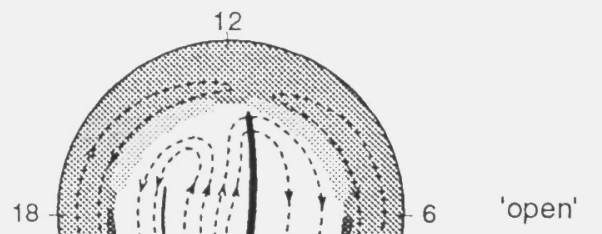

(b) 'bifurcated tail'

(c)

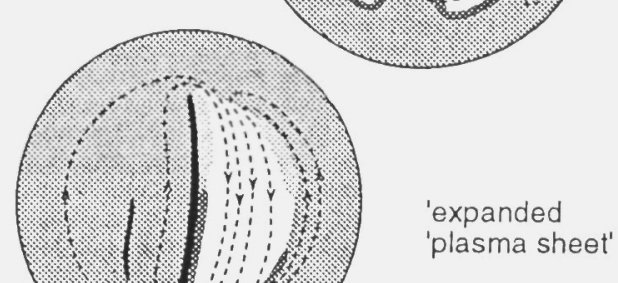

(d)

'expanded l|b|'
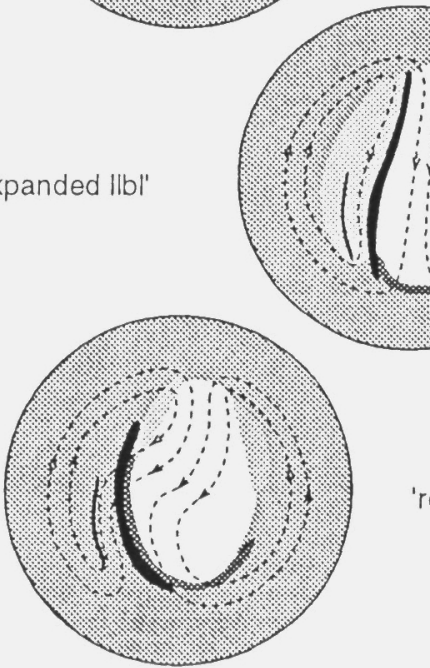

'rotated $x$-line'

Fig. 7. Schematic diagram of the mapping of the high-latitude ionosphere to the distant magnetotail for the $(a)$ 'open', $(b)$ 'bifurcated tail', (c) 'expanded plasma sheet', (d) 'expanded LLBL', and (e) 'rotated $\mathrm{x}$-line' models of polar cap morphology. A cross-section of the northern magnetotail lobe ( $y-z$ plane, looking from the tail sunward) is shown on the left, and the corresponding ionospheric convection pattern (dotted lines) and location of the sun-aligned and theta arc (solid lines), is shown on the right. Closed field line regions are shown in light gray (LLBL), medium gray (plasma sheet), and dark gray (PSBL), while open field line regions are shown in white. The solid dot in each figure on the left represents a field line threading the weak, sun-aligned arc at 22 MLT.

$\sim \mathrm{keV}$ ion precipitation and sunward plasma convection within ares which appeared to be flanked by open field lines [e.g., Kan and Burke, 1985; Frank et al., 1988; Frank and Craven, 1988]. This model has been supported by magnetotail observations of plasma sheet protrusions into the lobe [Iluang et al., 1987, 1989], and antiparallel merging models suggesting a split dayside merging line [Crooker, 1979; Toffoletto and Hill, 1990]. In a bifurcated tail scenario, weak, sun-aligned arcs observed on either side of a theta aurora occur on open field lines.

Both the expanded plasma sheet model and the expanded LLBL model (Figures 7 (c) and (d), respectively) propose that 
sun-aligned arcs occur on closed field lines threading a widened auroral oval. A closed field line source region of polar cap arcs has been supported by observations of trapped-particle signatures and the 'filled-in' nature of optical, electron, and ion measurements in the region between the average auroral oval and the polewardmost bright arc [Peterson and Shelley, 1984; Eliasson et al., 1987; Makita et al., 1991; Hones et al., 1989]. The difference between the expanded plasma sheet and LLBL models is really an issue of basic magnetospheric configuration; i.e., where the field lines in the widened auroral oval map to in the magnetosphere. In an expanded plasma sheet model, Figure 7 (c), the sun-aligned arc maps on closed field lines to an asymmetrically expanded plasma sheet in the tail. In the ionosphere, the region of open field lines is much smaller and shifted toward dawn to accommodate the expansion of the duskside oval; the theta aurora occurs at the poleward boundary of the expanded auroral oval, and the sun-aligned arc maps to the (sunward convecting) plasma sheet. This model was originally based on the continuous nature of simultaneous optical and electron precipitation measurements across the polar cap during quiet geomagnetic conditions [Meng, 1981, 1988; Murphree and Cogger, 1981; Murphree et al., 1982] and has been supported by observations of the poleward expansion of the soft $(<500 \mathrm{eV}$ ) electron precipitation region during northward IMF conditions [Makita et al., 1988; Rich et al., $1990]$.

In the expanded LLBL model, Figure 7 (d), the low-latitude boundary layer is significantly larger in the tail cross-section with the result that the sun-aligned arc ficld line maps to the antisunward convection region within the LLBL. The theta aurora, which maps to the boundary between open and closed field lines, is connected to the LLBL on the dayside and the plasma sheet boundary layer (PSBL) on the nightside [Lundin et al., 1990]. This model relies on an alternate view of solar wind - magnetosphere interaction in which the transfer of solar wind energy to the magnetosphere is primarily accomplished not through magnetic merging but through viscous interactions and actual mass transfer in the LLBL [Axford and Hines, 1961; Eastman et al., 1976; Sonnerup, 1980; Zhu and Kivelson, 1988; Stasiewicz, 1989]. Specifically, sun-aligned arcs map to polarization features resulting from finger-like injections of plasma into the LLBL [Lundin and Evans, 1985], which has been shown to widen during quiet times [Williams et al., 1985; Mitchell et al., 1987]. Vasyliunas [1979] argued that the LLBL should map to the ionosphere as a crescent shaped region near local noon; this projection would seem to be confirmed by studies of auroral oval-magnetosphere mapping using low-altitude particle measurements [e.g., Newell and Meng, 1992]. Studies using the Tsyganeko '87 and '89 magnetic field models have shown, however, that the ionospheric footprint of the LLBL (closed field lines near the dawn and dusk flanks of the magnetotail) may be significantly larger during quiet times, filling the region between a teardrop shaped polar cap and the auroral oval [Elphinstone et al., 1991; Birn et al.,1991].

The weak, sun-aligned arc system of February 27, 1987 can be examined in light of these models of polar cap arc forma- tion using the convection information presented in Section 3.1. Though arguably limited in spatial extent, the barium motion, radar l.o.s. velocities, and rocket electric field measurements indicate an extended region $(-400-500 \mathrm{~km})$ of antisunward convection in the region between the large sunaligned arc and the duskside auroral oval. Furthermore, the DMSP F-6 electron spectrogram shows an extended region of soft, sporadic electron precipitation poleward of the duskside auroral oval up to a magnetic latitude of $\sim 82^{\circ}$, where strong electron and ion precipitation signatures have been identified as a theta aurora over the center of the polar cap. The sunaligned arc identified by ASIP and the soft precipitation events encountered by the rocket lie within this precipitation zone (though further into the nightside than the DMSP pass). These observations may be accounted for by sun-aligned arc formation on closed field lines threading an expanded (antisunward convecting) LLBL, but are also consistent with a model in which they formed on open field lines on the dusk side of a bifurcated tail lobe (Figure 7 (b)). A model in which the polar cap is entirely open (Figure 7 (a)) appears to be ruled out, since it is inconsistent with the strong ion precipitation observed over the center of the polar cap (unless you invoke the Gussenhoven and Mullen [1989] scenario of an earthwardstreaming lobe ion component). The antisunward convection signature appears least consistent with a model in which the polar cap arc field lines map to an expanded plasma sheet (Figure 7 (c)), since one would expect sunward convection in this region.

Although it would seem clear (from both modeling and magnetotail measurements) that the ionospheric footprint of the LLBL should expand during quiet times, it is still questionable whether arcs deep within the nightside polar cap can be magnetically connected to this source. We are beginning to explore a different model of polar cap arc formation, shown in Figure 7 (e), which accounts for sun-aligned arcs (as well as their IMF $B_{y}$ dependence) at the poleward boundary of a closed field line region [Reiff et al., 1992]. In this model, a transpolar arc occurs as the result of the conductivity gradient across the ionospheric projection of the tail $x$-line, which is both sun-aligned and separated from the auroral oval for nearnorthward IMF $B_{z}$ [Toffoletto and Hill, 1992]. In this skewed plasma sheet geometry, the region between the sun-aligned arc (open-closed boundary) and the auroral oval (convection reversal boundary) maps to very long, plasma sheet ficld lines recently reconnected through the rotated $x$-line. In this sense the model is topologically an 'expanded plasma sheet' model, with the significant difference that the region between the $x$ line and the auroral oval is still convecting antisunward in the polar cap. Flow irregularities of plasma sheet or ionospheric origin could account for the presence of weak sun-aligned ares in this closed region.

\subsection{Electrodynamic Structure}

Figures 5 and 6 summarize the relationship between particle precipitation, cross-arc and parallel electric and magnetic field perturbations $\left(\delta \mathrm{E}_{x}\right.$ and $\left.\delta \mathrm{B}_{y}\right)$, field-aligned current density, and Poynting flux for the first and second precipitation events, 
respectively. Note the high degree of anti-correlation between $\delta \mathrm{B}_{\mathrm{y}}$ and $\delta \mathrm{E}_{\mathrm{x}}$ in Figures 5 and 6 . Smiddy et al. [1980] and Sugiura et al. [1982] have shown that anti-correlation between the perturbation magnetic field parallel to an infinite fieldaligned current sheet and the cross-sheet component of the electric field results from a combination of current continuity, Ohm's law, and Ampere's law such that $\Delta \mathrm{E}_{\mathrm{x}} / \Delta \delta \mathrm{B}_{\mathrm{y}}=-\left(\mu_{0} \Sigma_{\mathrm{p}}\right)^{-1}$, where $\Sigma_{p}$, the height-integrated Pedersen conductivity, is assumed to be uniform over the interval $\Delta x$. This relationship has been demonstrated with electric and magnetic field data acquired by the DE, HILAT and VIKING satellites [Sugiura et al., 1982; Sugiura, 1984; Vickrey et al., 1986; Bythrow et al., 1984] and several rocket experiments [Primdahl and Marklund, 1986; Primdahl et al., 1987]. The Polar ARCS measurements extend those results, showing that the relationship holds for $\delta \mathrm{B}$ perturbations of magnitude $\leq 10 \mathrm{nT}$. Using the measured values of $\delta B_{y}$ and $E_{x}$, the calculated height-integrated Pedersen conductivities in the two events fall between $0.4-0.5$ mho. As one would expect for such weak events, these values of $\Sigma_{P}$ are comparable (within experimental uncertainty) to the average background Pedersen conductivity $(0.6 \mathrm{mho})$ calculated from the Langmuir probe number density profile.

The current density in each event, shown in the third panel of Figures 5 and 6, respectively, was calculated using three different measurements: (1) magnetic field perturbations in the arc coordinate system $\left(\mathrm{j}_{\mathrm{z}}=\partial \mathrm{B}_{\mathrm{y}} / \mu_{0} \partial \mathrm{x}\right) ;(2)$ spatial variations in the cross-arc electric field and/or conductivity $\left(-j_{z}=\Sigma_{p}\right.$ $\left.\partial \mathrm{E}_{\mathrm{x}} / \partial \mathrm{x}+\mathrm{E}_{\mathrm{x}} \partial \Sigma_{\mathrm{p}} / \partial \mathrm{x}\right)$; and (3) precipitating electron fluxes $\left(\mathrm{j}_{\mathrm{z}}=\right.$ env $v_{d}$, where $n v_{d}$ is the electron flux over the downcoming hemisphere). The first two calculations yield well-correlated, paired, upward and downward field-aligned currents of densities between 1-2 $\mu \mathrm{A} / \mathrm{m}^{2}$, with the upward currents associated with regions of $\nabla \cdot \mathbf{E}<0$. The currents computed using the number flux measurements are upward throughout both events due to the fact that a significant portion of the downward current is carried by thermal electrons with energies less than $10 \mathrm{eV}$ [Burch et al., 1983]; with the addition of an onboard noise source, low-energy upflowing electrons and thus downward current regions were undetectable [Weiss, 1991]. Magnetosphere-ionosphere coupling models have shown that locally-closed, paired, upward and downward field-aligned currents in polar cap arcs can result from either mesoscale velocity shear structures in the ionosphere [Chiu, 1989], or from multiply-bouncing Alfvén waves originating at mesoscale velocity shear structures in the magnetosphere [Zhu et al., 1993]. The latter model predicts a paired current structure scale size of tens of kilometers, with a spacing between arcs on the order of $50 \mathrm{~km}$.

The energy flux into the ionosphere due to particle precipitation is plotted in the top panels of Figures 5 and 6 to show the relationship between particle precipitation and the fieldaligned current density. One would normally expect the maximum particle energy flux to be coincident with an upward field-aligned current. In both events, however, the maximum energy flux is displaced by $-5 \mathrm{~s}$ from the region of peak upward current, a situation not observationally uncommon in auroral arcs [Lu et al., 1991]. This displacement may be explained by either an asymmetric parallel potential drop or by mapping to a nonuniform density structure in the magnetosphere. A second form of energy input into the high-latitude ionosphere is through the Joule dissipation of electromagnetic energy. Kelley et al. [1991] have shown that a reliable measure of electromagnetic energy flux into the ionosphere is the vertical component of the Poynting flux, in this case, $P_{z}=E_{x} \delta B_{y} / \mu_{0}$, plotted in the bottom panels of Figures $S$ and 6 in units of erg $/$ $\mathrm{cm}^{2}-\mathrm{s}$. In both events the Poynting flux is downward, indicating a transfer of energy from the magnetosphere to the ionosphere. The maximum electromagnetic energy input is comparable to the kinetic input due to particle precipitation (but both are significantly smaller than the $1-10 \mathrm{erg} / \mathrm{cm}^{2}-\mathrm{s}$ typically observed in auroral oval arcs). Note also that the Poynting flux maximizes in the region between upward and downward currents (where the product of the quantities $E_{x}$ and $\delta B_{y}$ have their largest values), while the maximum energy flux due to electron precipitation is displaced toward the upward current region, a situation expected in a paired current sheet geometry.

\section{SUMMARY AND CONCLUSIONS}

Radar, optical, and in situ (rocket and satellite) data from the Polar ARCS campaign have been presented and used to analyze the electrodynamic structure of a weak, sun-aligned arc within the duskside polar cap as well as its relationship to large-scale magnetospheric boundaries. Electron precipitation measurements indicate that the rocket passed through three narrow ( $\leq$ $20 \mathrm{~km})$ regions of low-energy $(\leq 100 \mathrm{eV})$ electron precipitation. These events are interpreted as small-scale structures that lie within a region of weak, sun-aligned precipitation in the region between the auroral oval and the brightest sun-aligned arc in the all-sky images. DMSP F-6 measurements of enhanced ion and electron precipitation over the center of the polar cap further suggests the presence of a transpolar ('theta') aurora at this time.

The relationship between the high latitude ionosphere and the magnetosphere, especially the question of whether field lines on which polar cap arcs occur are open or closed, has been widely debated and remains one of the outstanding topics of magnetospheric physics today. In this paper we have used one aspect of the Polar ARCS measurements, namely the antisunward convection signature in the region between the sunaligned arc and the dusk-side auroral oval, as a means of evaluating different models of polar cap arc formation. The observed convection (as determined by the radar l.o.s. velocity measurements, barium convection data, and electric field double probe measurements) is least consistent with a model in which the auroral field lines map to an expanded plasina sheet [Meng, 1981; Murphree et al., 1982], since one would expect sunward convection on these reconnected field lines. An exception to the expected sunward convection signature on plasma sheet field lines might arise if the polar cap arc inaps to field lines recently reconnected through a highly skewed $x$-line [Reiff et al., 1992]; in this case, the ionospheric end of the field line may still be convecting antisunward even though it 
is moving earthward in the plasma sheet. The antisunward convection signature is also consistent with a model in which the weak, sun-aligned arc system formed on open field lines on the dusk side of a bifurcated tail lobe [e.g., Kan and Burke, 1985; Frank and Craven, 1988; Toffoletto and Hill, 1990] or a model in which it formed on closed field lines threading the low-latitude boundary layer [Lundin and Evans, 1985; Lundin et al. 1990]. In the latter case, however, we note that while the teardrop shape of the quict-time auroral oval can be accounted for by the expansion of the LLBL away from the dayside cleft, it seems unlikely that arcs deep within the nightside polar cap can be topologically attributed to this source. To date, the authors are unaware of an extended (statistical) study of ionospheric convection in the region between sun-aligned arcs and the nearby auroral oval using satellite data. As demonstrated in this paper, such a study may help evaluate competing models of polar cap arc formation and thus determine the source region(s) of these arcs.

Very weak but highly correlated electric and magnetic field perturbations made aboard the Polar ARCS instrumented rocket indicate that the weak, F-layer precipitation events crossed by the rocket are associated with small-scale, paired, field-aligned current sheets. The correlation of $\delta B_{y}$ and $E_{x}$ imply uniform $\Sigma_{p}$ and provides a measure of that quantity, in this case $\sim 0.4-0.5$ mho, values consistent with that calculated from the Langmuir probe measurements. The current density in each event was calculated using the magnetic field (Ampere's Law), electric field (current divergence plus Ohm's law), and particle precipitation measurements, yielding well correlated ficld-aligned currents of densities between 1-2 $\mu \mathrm{A} / \mathrm{m}^{2}$. The upward and downward current regions can be associated with velocity shears (higher and lower speed streams) embedded in a region of anti-sunward flow. Such mesoscale shear flows in association with polar cap arcs have been confirmed by many observations [Carlson et al., 1984; Hoffman et al., 1985; Mende et al., 1988; Weber et al., 1989 Valladares and Carlson, 1991]. These velocity shears appear to be of magnetospheric origin since the Poynting flux is predominately downward in the vicinity of the arcs. If the weak, sun-aligned arcs formed on open field lines in a bifurcated tail geometry, the velocity shears map to regions of the magnetosheath where nonuniform flow may be easily accounted for. If the arcs map to the LLBL, the velocity shears may result from finger-like injections of magnetosheath plasma onto closed LLBL field lines, or, if they map to a highly skewed plasma sheet, the velocity shears may originate as bursty flows in the tail. In all cases, the visual emissions are produced in the upward current regions by precipitating electrons carrying the outgoing current from the electric field divergence.

Acknowledgments. The authors would like to acknowledge the Danish Commission for Scientific Research in Greenland for pernission to conduct the Polar ARCS experiments. We also thank Jim Vicksey of SRI, Bob Robinson of LPARL, Rudy Frahm of SwRI, and the two referees for their help in improving and evaluating this paper. Information critical to the analysis of the magnetometer and electron spectrometer data was supplied by Poul Jensen, Carl Bargainer, Jolın Scherrer, and Nick Eaker of SwRI. We thank DuWayne Bostow of the
Geophysical Institute for managing the high explosive shaped clarges and machining the barium metal cones, and Gale Weeding of the Denver Research Institute for fabricating the high explosive Octol charges. We would also like to thank the personnel of NASA Wallops Flight Facility, and in particular Jay Brown, the payload manager for payload fabrication and launch support. This research was supported at Southwest Research Institute under Phillips Laboratory grant AFOSR87-0203, at Rice University by NASA under grant NAGW 1655 and by the National Science Foundation under grant ATM-91-03440, at Phillips Laboratory by AFOSR task 2310G9, and at the University of Alaska at Fairbanks by NASA under grant NAG6-1.

\section{REFERENCES}

Axford, W. I., and C. O. Hines, A unifying theory of high-latitude geophysical phenomena and geomagnetic storms, Can. J. Phys., 39, 1433, 1961.

Birn, J., E. W. Hones, Jr., J. D. Craven, L. A. Frank, R. D. Elphinstone, and D. P. Stern, On open and closed field line regions in Tsyganenko's field model and their possible associations with horse collar auroras, J. Geophys. Res., 96, 3811, 1991.

Burch, J. L., P. H. Reiff, M. Sugiura, Upward electron beams measured by DE-1: A primary source of dayside region-1 Birkeland currents, Geophys. Res. Lett., 10, 753, 1983.

Burke, W. J., M. C. Kelley, R. C. Sagalyn, M. Smiddy, and S. T. Lai, Polar cap electric field structures with a northward interplanetary magnetic field, Geophys. Res. Lett., 6, 21, 1979.

Burke, W. J., M. S. Gussenhoven, M. C. Kelley, D. A. Hardy, and F. J. Rich, Electric and magnetic field characteristics and discrete arcs in the polar cap, J. Geophys. Res., 87, 2431, 1982.

Bythrow, P. F., T. A. Potemra, W. B. Hanson, L. J. Zanetti, C.-I. Meng, R. E. Huffman, F. J. Rich, and D. A. Hardy, Earthward directed highdensity Birkeland currents observed by HILAT, . Geophys. Res., 89 , 9114, 1984.

Carlson, H. C., V. B. Wickwar, E. J. Weber, J. Buchau, J. G. Moore, and W. Whiting, Plasma characteristics of polar-cap F-layer arcs, Geophys. Res. Lett., 9, 895, 1984.

Chiu, Y. T., Formation of polar cap arcs, Geophys. Res. Lett., 16, 125, 1989.

Chiu, Y. T., and D. J. Gorney, Eddy intrusion of hot plasma into the polar cap and formation of polar cap arcs, J. Geophys. Res., 85, 543, 1980.

Chiu, Y. T., and D. J. Gorney, Eddy intrusion of hot plasma into the polar cap and formation of polar cap arcs, Geophys. Res. Lett., 10, $463,1983$.

Chiu, Y. T., N. U. Crooker, and D. J. Gorney, Model of oval and polar cap arc configurations, J. Geophys. Res., 90, 5153, 1985.

Eastman, T. E., E. W. Hones, Jr., S. J. Bame, and J. R. Asbridge, The magnetospheric boundary layer: site of plasma, momentum and energy transfer from the magnetosheath into the magnetosphere, Geophys. Res. Lett., 3, 685, 1976.

Eliasson, L., R. Lundin, and J. S. Murphree, Polar cap arcs observed by the Viking satellite, Geophys. Res. Lett., 14, 451, 1987.

Elphinstone, R. D., K. Jankowska, J. S. Murphree, and L. L. Cogger, The configuration of the auroral distribution for interplanetary magnetic field $\mathrm{B}_{7}$ northward: 1 . IMF $\mathrm{B}_{\mathrm{x}}$ and $\mathrm{B}_{\mathrm{y}}$ dependencies as observed by the Viking satellite, J. Geophys. Res., 95, 5791, 1990.

Elphinstone, R. D., D. Hearn, J. S. Murphree, and L. L. Cogger, Mapping using the Tsyganenko long magnetospheric model and its relationship to Viking Auroral Images, J. Geophys. Res., 96, 1467, 1991.

Frank, L. A., J. D., Craven, J. L. Burch, and J. D. Winningham, Polar views of the Earth's aurora with Dynanics Explorer, Geophys. Res. Lett., 9, 1001, 1982.

Frank, L. A., J. D. Craven, D. A. Gurnett, S. D. Slıawhan, D. R. Weimer, J. L. Burch, J. D. Winningham, C. R. Chappell, J. H. Waite, R. A. Heelis, N. C. Maynard, M. Sugiura, W. K. Peterson, and E. G. Shelley, The theta aurora, J. Geophys. Res., 91, 3177, 1986.

Frank, L. A., and J. D. Craven, Imaging results from Dynamics Explorer 1, Rev. Geophys., 26, 249, 1988. 
Gussenhoven, M. S., and E. G. Mullen, Simultaneous relativistic electron and auroral particle access to the polar caps during interplanetary magnetic field $B_{z}$ northward: A scenario for an open field line source of auroral particles, J. Geophys. Res., 94, 17,121, 1989.

Hardy, D. A., W. J. Burke, and M. S. Gussenhoven, DMSP optical and electron measurements in the vicinity of polar cap arcs, J. Geophys. Res., 87, 2413, 1982.

Hardy, D. A, Intense fluxes of low-energy electrons at geomagnetic latitudes above $85^{\circ}$, J. Geophys. Res., 89, 3883, 1984.

Heelis, R. A., J. D. Winningham, W. B. Hanson, and J. L. Burch, The relationships between high-latitude convection reversals and the energetic particle morphology observed by Atmospheric Explorer, $J$. Geophys. Res., 85, 3315, 1980.

Hoffman, R. A., R. A. Heelis, and J. S. Prasad, A sun-aligned arc observed by DMSP and AE-C, J. Geophys. Res., 90, 9697, 1985.

Hones, E. W., Jr, J. D. Craven, L. A. Frank, D. S. Evans, and P. T. Newell, The horse-collar aurora: A frequent pattern of the aurora in quiet times, Geophys. Res. Lett., 16, 37, 1989.

Huang, C. Y., L. A. Frank, W. K. Peterson, D. J. Williams, W. Lennartsson, D. G. Mitchell, R. C. Elphic, and C. T. Russell, Filamentary structures in the magnetotail lobes, J. Geophys. Res., 92, $2349,1987$.

Huang, C. Y., L. A. Frank, J. D. Craven, Simultaneous observations of a theta aurora and associated magnetotail plasmas, J. Geophys. Res., 94, 10137,1989 .

Lijima, T., T. A. Potemra, L. J. Zanetti, and P. F. Bythrow, Large-scale Birkeland in the dayside polar region during strongly northward IMF: A new Birkeland current system, J. Geophys. Res., 89, 7441, 1984.

Kan, J. R., and W. J. Burke, A theoretical model of polar cap auroral arcs, J. Geophys. Res., 90, 4171, 1985.

Kelley, M. C., D. J. Knudsen, and J. F. Vickrey, Poynting flux measurements on a satellite: a diagnostic tool for space research, J. Geophys. Res., 96, 201, 1991.

Lassen, K., and C. Danielsen, Quiet time pattern of auroral arcs for different directions of the interplanetary magnetic field in the Y-Z plane, J. Geophys. Res., 83, 5277, 1978.

Lassen, K., and C. Danielsen, Distribution of auroral arcs during quiet geomagnetic conditions, J. Geophys. Res., 94, 2587, 1989.

Lu, G., P. H. Reiff, J. L. Burch, and J. D. Winningham, On the auroral current-voltage relationship, J. Geophys. Res., 96, 3523, 1991.

Lundin, R., and D. S. Evans, Boundary layer plasmas as a source for high-latitude, early afternoon, auroral arcs, Planet. Space Sci., 32, $1389,1985$.

Lundin, R., L. Eliasson, J. S. Murphree, The quiet-time aurora and the magnetosphere configuration, in Auroral Physics, ed. C.-I. Meng, M. J. Rycroft, and L. A. Frank, p.159, Cambridge University Press, Cambridge, U.K., 1990.

Lyons, L. R., Generation of large-scale regions of auroral currents, electric potentials, and precipitation by the divergence of the convection electric field, J. Geophys. Res., 85, 17, 1980.

Makita, K., C.-I. Meng, and S.-I. Akasofu, Latitudinal electron precipitation patterns during large and small IMF magnitudes for northward IMF conditions, J. Geophys. Res., 93, 97, 1988.

Makita, K., C.-I. Meng, and S.-I. Akasofu, Transpolar auroras, their particle precipitation and IMF By component, J. Geophys. Res., 96, $14085,1991$.

Mende, S. B., J. H. Doolittle, R. M. Robinson, R. R. Vondrak, and F. J. Rich, Plasma drifts associated with a system of sun-aligned arcs in the polar cap, J. Geophys. Res., 93, 256, 1988.

Meng, C.-I., Polar cap arcs and the plasma sheet, Geophys. Res. Lett., 8, 273, 1981

Meng, C.-I., Auroral oval configuration during the quiet condition, in Electromagnetic Coupling in the Polar Clefts and Caps, ed. R. E. Sandholt and A. Egeland, p.61, Kluwer Academic Publishers, Dordrecht, Netherlands, 1988.

Mikkelsen, I. S., Drift of the Ba-jets released over Greenland on February 26 and March 5, 1987, Progress Report for Grant AFOSR87-0203, Danish Meteorological Institute, Copenhagen, Denmark, 1987.
Mitchell, D. G., F. Kutchko, D. J. Williams, T. E. Eastman, L. A. Frank, and C. T. Russell, An extended study of the low-latitude boundary layer on the dawn and dusk flanks of the magnetosphere, J. Geophys. Res., 92, 7394, 1987.

Murphree, J. S., and L. L. Cogger, Observed connections between apparent polar cap features and the instantaneous diffuse auroral oval, Planet. Space Sci., 29, 1143, 1981.

Murphree, J. S., C. D. Anger, and L. L. Cogger, The instantaneous relationship between polar cap and oval auroras at times of northern interplanetary magnetic field, Can. J. Phys., 60, 349, 1982.

Newell, P. T., W. J. Burke, C.-I. Meng, E. R. Sanchez, and M. E. Greenspan, Identification and observations of the plasma mantle at low altitude, J. Geophys. Res., 96, 35, 1991.

Newell, P. T., and C.-I. Meng, Mapping the dayside ionosphere to the magnetosphere according to particle precipitation characteristics, Geophys. Res. Lett., 19, 609, 1992.

Nielsen, E., J. D. Craven, L. A. Frank, and R. A. Heelis, Ionospheric flows associated with a transpolar arc, J. Geophys. Res., 95, 21169 , 1990.

Peterson, W. K., and E. G. Shelley, Origin of the plasma in a cross-polar cap auroral feature (theta aurora), J. Geophys. Res., 89, 6729, 1984.

Primdahl, F., The fluxgate magnetometer, J. Phys. E: Sci. Instrum., 12, $241,1979$.

Primdahl, F. and G. Marklund, Birkeland currents correlated with directcurrent electric fields observed during the CENTAUR Black Brant X rocket experiment, Can. J. Phys., 64, 1412, 1986.

Primdahl, F., G. Marklund, and I. Sandahl, Rocket observations of E-B field correlations showing up- and down-going Poynting flux during an auroral breakup event, Planet. Space Sci., 35, 1287, 1987.

Reiff, P. H., J. L. Burch, and R. A. Heelis, Dayside auroral arcs and convection, Geophys. Res. Lett., S, 391, 1978.

Reiff, P. H. and J. L. Burch, IMF By-dependent plasma flow and birkeland currents in the dayside magnetosphere 2. A global model for northward and southward IMF, J. Geophys. Res., 90, 1595, 1985.

Reiff, P. H., F. R. Toffoletto, L. A. Weiss, and J. S. Murphree, A new model of polar cap convection and auroral arcs during northward IMF, EOS, Transactions, 73, p.466, 1992.

Rich, F. J., D. A. Hardy, R. H. Redus, and M. S. Gussenhoven, Northward IMF and patterns of high-latitude precipitation and fieldaligned currents: The February 1986 Storm, J. Geophys. Res., 95, $9893,1990$.

Roble, R. G., and M. H. Rees, Time-dependent studies of the aurora: effects of particle precipitation on the dynamic morphology of ionospheric and atmospheric properties, Planet. Space Sci., 25, 991 , 1977.

Sharber, J. R., J. D. Winningham, J. R. Scherrer, M. J. Sablik, C. A. Bargainer, P. A. Jensen, B. J. Mask, and N. Eaker, Angle resolving energy analyzer (AREA): A versatile "top-hat" instrument for space plasma measurement, IEEE Transactions on Geosciences and Renote Sensing, 474, 1988.

Smiddy, M., W. J. Burke, M. C. Kelley, N. A. Saflekos, M. S. Gussenhoven, D. A. Hardy, and F. J. Rich, Effects of high-latitude conductivity on observed convection electric fields and Birkeland currents, J. Geophys. Res., 85, 6811, 1980.

Sonnerup, B. U. O., Theory of the low-latitude boundary layer, $J$. Geophys. Res., 85, 2017, 1980.

Stasiewicz, K., A fluid finite ion larmor radius model of the magnetopause layer, J. Geophys. Res., 94, 8827, 1989.

Sugiura, M., N. C. Maynard, W. H. Farthing. J. P. Heppner, and B. G. Ledley, Initial results on the correlation between the magnetic and electric fields observed from the DE-2 satellite in the field-aligned current regions, Geophys. Res. Lett., 9, 985, 1982.

Sugiura, M., A fundamental magnetosphere-jonospliere coupling mode involving field-aligned currents as deduced from DE-2 observations, Geophys. Res. Lett., 11, 877, 1984.

Toffoletto, F. R., and T. W. Hill, Magnetic field configuration of the theta aurora, Geophys. Res. Lett., 17, 595, 1990.

Toffoletto, F. R., and T. W. Hill, A non-singular model of the open magnetosphere, accepted for publication, J.Geophys.Res., Sept., 1992. 
Torbert, R. B., C. A. Cattell, F. S. Mozer, and C.-I. Meng, The boundary of the polar cap and its relation to electric fields, field-aligned currents, and auroral particle precipitation, in Physics of Auroral Arc Formation, Geophys, Monogr. Ser., vol. 25, edited by S.-I. Akasofu and J. R. Kan, p.143, Washington D.C., AGU, 1981.

Valladares, C. E., and H. C. Carlson, Jr., The electrodynamic, thermal, and energetic character of intense sun-aligned arcs in the polar cap, J. Geophys. Res., 96, 1379, 1991.

Vasyliunas, V. M., Interaction between the magnetospheric boundary layers and the jonosphere, in Proceedings of Magnetospheric Boundary Layers Conference, ESA SP-148, p.387, 1979.

Vickrey, J. F., R. C. Livingston, N. B. Walker, T. A. Potemra, R. A. Heelis, M. C. Kelley, and F. J. Rich, On the current-voltage relationship on the magnetospheric generator at intermediate spatial scales, Geophys. Res. Lett., 13, 495, 1986.

Weber, E. J., and J. Buchau, Polar cap F layer auroras, Geophys. Res. Lett., 8, 125, 1981.

Weber, E. J., M. C. Kelley, J. O. Ballenthin, S. Basu, H. C. Carlson, J. R. Fleischman, D. A. Hardy, N. C. Maynard, R. F. Pfaff, P. Rodriguez, R. E. Sheehan, and M. Smiddy, Rocket measurements within a polar cap arc: Plasma, particle, and electric field circuit parameters, $J$. Geophys. Res., 94, 6692, 1989.

Weiss, L. A., A study of high-latitude auroral arcs using radar, optical, and in situ techniques, Ph.D. Thesis, Rice University, Houston, TX, October, 1991.

Williams, D. J., D. G. Mitchell, T. E. Eastman, and L. A. Frank, Energetic particle observations in the low-latitude boundary layer, $J$. Geophys. Res., 90, 5097, 1985.

Winningham, J. D., and W. J. Heikkila, Polar cap auroral electron fluxes observed with ISIS I, J. Geophys. Res., 79, 949, 1974.

Zanetti, T. A. Potemra, R. E. Erlandson, F. F. Bythrow, B. J. Anderson, J. S. Murphree, and G. T. Marklund, Polar region Birkeland current, convection, and aurora for northward interplanetary magnetic field, J. Geophys. Res., 95, 5825, 1990.

Zhu, L., J. J. Sojka, R. W. Schunk, and D. J. Crain, A time-dependent model of polar cap arcs, in press, J. Geophys. Res., 1993.

Zhu, X., and M. G. Kivelson, Analytic formulation and quantitative solutions of the coupled ULF wave problem, J. Geophys. Res., 93, $8602,1988$. 